\title{
SABER TREINAR A SI MESMO: PORQUE E COMO DEVEMOS ENSINAR TREINAMENTO NAS AULAS DE EDUCAÇÃO FÍSICA?
}

DOI: 105902/0102830821689

Artigo Convidado

Reiner Hildebrandt-Stramman

Technische Universität Braunschweig hildebrandt-stramann@t-online.de

Celi Zulke Taffarel

Universidade Federal da Bahia taffarel@ufba.br

RESUMO: O texto apresenta argumentações cientificas sobre o treino corporal na escola a partir de uma experiência concreta na Escola Municipal Teodoro Sampaio, Salvador, Bahia, Brasil.

Palavras-chave: Treino corporal. Educação física. Escola. 


\section{Introdução}

Nos últimos dez anos podemos considerar que ocorreu uma alteração de paradigma na discussão sobre a relevância do tema "treinamento" na escola. Até o inicio do século XX predominou uma compreensão de treinamento nas escolas orientadas nas normas do esporte, em especial o esporte do alto rendimento e era destinado aos poucos que treinavam alguma modalidade esportiva para competir em jogos escolares. Esta concepção mudou para uma compreensão pedagógica de treinamento. Os critérios de aplicação, controle e aumento da intensidade nos treinos não são mais as metas máximas a qualquer custo, mas, sim, uma avaliação subjetiva da carga e, ligado a isto um aumento da capacidade de rendimento com base em normas subjetivas de carga e do domínio de um conhecimento científico sobre suas capacidades humanas e as consequências do treino esportivo.

O presente artigo situa-se entre os que tratam do treino esportivo na escola e surge na sequência desta nova discussão. Em primeiro lugar são apresentadas argumentações pedagógicas que fundamentam tratar sobre o conteúdo do treino na educação física escolar. Na sequencia será discutida a questão da metodologia do ensino a partir da pergunta sobre como treinar nas aulas da educação física na escola. Por fim, é apresentado para reflexão um exemplo do trato com o conteúdo treinamento de força e resistência nas aulas de Educação Física com base nesta nova argumentação pedagógica e metodológica.

\section{Por que treinar nas aulas da educação física?}

Apresentamos duas respostas a esta pergunta, fundamentadas teoricamente nas reflexões educacionais sobre a Educação Física (comp. Hildebrandt-Stramann, 2013, pp. 117-194). O objetivo geral da educação física é de educar os alunos para serem capazes de atuar (comp. Hildebrandt-Stramann \& Taffarel, 2007, pp. 25-30). Mas os alunos somente serão capazes de atuar com autonomia e autoorganização se assimilarem conhecimentos clássicos que permitem elevar a 
capacidade teórica. Isto significa que na aula da educação física, ao tratar do tema do treinamento eles devem dominar os conteúdos clássicos que lhes permitam treinar a si mesmo, mas, também conhecer os problemas do treino e saber tratar os mesmos de maneira critica (comp. Hildebrandt-Stramann, 2013, pp. 27-49). Os objetivos específicos em relação ao tema de treinamento na escola são dois:

1. Elucidar alunos, ampliando suas referencias teóricas sobre treino;

2. Coletar, sistematizar e analisar experiências corporais com o treino.

A seguir estes dois objetivos precisam ser esclarecidos.

\subsection{Elucidar alunos ampliando referencias teóricas sobre treino}

O potencial especial de educação do treinamento estana relação pessoal dos alunos com os conhecimentos científicos do treinamento e na utilização pessoal na própria vida e não na utilização irrefletida destes conhecimentos. Para esta utilização consciente entram nos estudos os conteúdos sobre:

- a reflexão crítica dos conhecimentos tecnológicos;

- o perigo imanente da alienação e manipulação e;

- a determinação dos limites de rendimento no processo de treino.

Não faz sentido eliminar do currículo escolar o conteúdo treinamento das aulas de Educação Física frente a necessidade concreta da realidade atual considerando os temas mencionados acima. Estes temas são contemporâneos, atuais e necessários de serem tratados como conhecimentos clássicos e portanto fundamentais no currículo escolar que deve nuclear as principais experiências dos alunos na escola.

Um objetivo geral para o tratamento do tema treinamento nas escolas pode ser formulado de seguinte maneira:

Os alunos devem aprender na escola - não há outro lugar para isto - a tratar os temas da construção, da reconstrução e do melhoramento do status quo biofísico de maneira crítica. Discutir com base em conhecimentos científicos as 
possibilidades metodológicas, mas, também, os perigos do treinamento. Somente com isso eles ganham experiências, conhecimentos e uma competência especifica de treino, com a qual podem se emancipar das formas externas de controle e agir com autonomia e autodeterminação.

O ponto de partida para realizar este objetivo são os nexos e relações entre a teoria acumulada e a prática concreta de cada aluno - cada individuo singular - para assimilar o que é produzido histórica e coletivamente pela humanidade (SAVIANI, 2013, p. 13). É de responsabilidade do professor transmitir o conhecimento clássico sobre treino, ou seja, aquilo que tem caráter permanente, que é saber sistematizado, que implica em dosar e sequenciar de modo que os alunos possam passar do não domínio para o domínio do conhecimento treino, como conhecimento escolar.

Conhecer os princípios do treinamento esportivo é conhecer um conhecimento clássico que deve ser assegurado na escola. Não por meio de aulas ditas teóricas mas, sim, pela atividade principal das aulas de Educação Física. Na Teoria sobre treinamento vamos encontrar seus princípios básicos. Segundo Tubino estes princípios se intercruzam em todas as suas aplicações e são os seguintes: O Princípio da Individualidade Biológica, O Princípio da Adaptação, O Princípio da Sobrecarga, O Princípio da Continuidade, O Princípio da Interdependência Volume-Intensidade (TUBINO, 1984). Vamos enfatizar na presente experiência as noções de singularidade e carga.

O treino deve estar, portanto, compondo o conjunto das atividades nucleares distribuídas no espaço e tempo escolar para que a escola cumpra seu papel que é transmitir-assimilar o conhecimento clássico e o currículo cumpra seu papel que é contribuir para elevar a capacidade teórica dos alunos. Sem o domínio, sem o automatismo, sem a elevação da capacidade teórica, os alunos não tem como serem criativos, autônomos e independentes (SAVIANI, 2013, pp. 11-20).

Mas como fazer isto de forma que os alunos estruturem um conhecimento com base na formação da imagem subjetiva da realidade objetiva? A primeira explicação nos advém da teoria histórico-cultural que explica o desenvolvimento 
do psiquismo humano e aqui vamos nos valer das exposições da professora Ligia Martins a respeito do processo funcional da sensação e da percepção. Martins (2013, pp. 117-141) Explica que o requisito primário da sensação é a captação sensorial de substrato fisiológico.

Valendo-se dos estudos de Luria (1991, pp 8-9) Martins explica que são as sensações proprioceptivas, que respondem ao principio da complexidade porque intercruzam três grandes grupos de sensações a saber: interoceptivas, proprioceptivas e extroceptivas. As sensações se interpenetram com a percepção formando uma unidade funcional apesar das propriedades que lhes são próprias e diferenciadas. Ainda segundo Martins (2013, p. 130) a percepção reflete o conjunto de propriedades, possibilitando a construção de uma imagem unificada das sensações. É, portanto, segundo Luria (1991, p.38) citado por Martins (2013, p. 131) a percepção que permitira atribuir um significado às impressões sensoriais proprioceptivas.

No nosso caso atribuir significado as sensações e percepções subjetivas de uma tarefa objetiva, o treino corporal de força e resistência. Com isto passasse a ter um conhecimento subjetivo sobre treinamento que se objetiva em novas ações no treinamento. A percepção vem de processo funcionais complexos de analise e síntese e de processos de comparações. São funções que se desenvolvem com a atividade, a saber, a atividade sensitiva e perceptiva. Portanto, as experiências passadas sobre treino, bem como, a analise das experiência atuais pelas sensações e percepções, possibilitarão um salto qualitativo no conhecimento sobre treino corporal de força e resistência. O caráter sintético da percepção e suas fusões primarias entre percepção, linguagem e pensamento incidem na consciência sobre a realidade concreta a respeito deste fenômeno humano - treinamento corporal. Portanto, as sensações e percepções são processos funcionais vinculadas à constituição da consciência.

Para isto funcionar é preciso a atividade principal, orientadora desta construção. É o que veremos a seguir quando tratamos sobre treino de força e resistência 
nas aulas de Educação Física. Priorizamos as valências força e resistência mas, existem, segundo diferentes classificações, apresentadas por diferentes autores (HEYWARD, 2004), outras valências como: flexibilidade, velocidade, e ainda potencia, coordenação e equilíbrio.

\subsection{Coletar, sistematizar e analisar experiências corporais com o treino}

A ação "treinar"1 torna-se pedagogicamente significativa para os alunos quando os mesmos conhecem, através do treinamento e com suas próprias experiências corporais o que é esforço, cansaço, capacidade de carga e relaxamento. Partindo do conceito humanista de ser humano eles devem conhecer seus corpos, vivenciando, sistematizando e analisando as alterações do estado biofísico, no sentido de modificações, de aumento e de diminuições resultantes do esforço físico. Eles devem saber que somente podemos nos fortalecer nos enfraquecendo.

A importância pedagógica do treinamento está na experiência corporal imediata. Mas não é qualquer experiência e muito menos a experiência com comandos impostos. Cargas de treinamento, conscientemente experimentadas, podem ajudar os alunos a conhecer melhor suas capacidades, habilidades e competências biofísicas. Aí reside a oportunidade de autoconhecimento imediato. Experiências conscientes do seu corpo são equivalentes aos de aprendizagem social.

Portanto, os alunos devem aprender a refletir sobre como seu corpo reage aos estímulos de treinamento sistemático. Eles devem aprender que as cargas de treinamento moderado podem ser não só estressante, mas, também, relaxante. Assim, é simultaneamente ligado a experiência que o desempenho físico não é um modelo teórico, mas pode ser ativamente influenciado e melhorado e ainda pode aumentar o bem-estar pessoal. Ponto de partida para todas as outras considerações educacionais é a questão de como o professor pode orientar

\footnotetext{
${ }^{1}$ Destacamos que a literatura da área da Educação Física/Ciência do Esporte traz uma vasta relação de trabalhos sobre a Ciência do Treino Esportivo. Vamos nos ater a discussão de caráter pedagógico.
} 
os alunos através de tal experiências corporais subjetivas para atividades de treinamento auto-responsáveis e auto-decididas.

\section{Como treinar nas aulas da educação física escolar?}

A pergunta "como" treinar está relacionada com o objetivo: os alunos aprendem a avaliar e controlar as cargas de treinamento. Padrões de carga tradicionais, tais como a duração da carga, a extensão e a intensidade da carga sugerem uma lógica de planejamento para o processo de treinamento. Mas estes critérios não são suficiente para a configuração de um processo subjetivo de treinamento, ou seja, um processo onde as sensações e a percepção de cada individuo singular são captadas, sistematizadas, analisadas. Expande-se assim a dimensão das cargas pela dimensão subjetivada carga.

Nesta dimensão subjetiva trata-se das sensações, percepções e da detecção de tensões/ cargas internas, causadas por cargas externas. Os alunos devem aprender a dosar cargas individuais corretamente e verificar os resultados do estresse da carga de treinamento por meio de seu próprio esforço percebido subjetivamente. Além disso os alunos devem aprender, que essa avaliação no caso de um desequilíbrio entre o esforço de formação e as sequências de tensão leva a uma nova regulação da intensidade do exercício. Considerando essas experiências subjetivas do treinamento, o treino é avaliado quantitativa e qualitativamente através da qualidade subjetiva.

Para os alunos é importante vivenciar as cargas de maneira positiva. Os requisitos de carga devem ser escolhidos de modo que eles são, por um lado, subjetivamente tolerável, mas no outro lado estimulem processos de adaptação fisiológicos. Portanto, os alunos devem ser capazes de adaptar a dosagem de carga pelo tato sensível, questionando assim suas próprias condições, competências e habilidades. As habilidades e competências de ser capaz de controlar um processo de treinamento de acordo com as suas necessidades subjetivas mostram se no sucesso do processo de reconciliação entre a dosagem das cargas objetivas 
e subjetivas. Os alunos podem demonstrar se eles conseguem construir um equilíbrio entre as cargas objetivas e as cargas subjetivas, a partir dos esforços subjetivamente percebidos.

3 Como pode ser configurado um processo de ensino na aula de educação física, onde os alunos aprendem construir um equilíbrio entre as cargas objetivas (a duração da carga, a extensão e a intensidade da carga) e as cargas subjetivas (as sensações e percepções subjetivas dos esforços)?

Vamos responder a esta pergunta complexa com a descrição e reflexão de dois exemplos práticos com temas fundamentais do treinamento: o desenvolvimento da resistência e da força.

\subsection{Alunos treinam sua força e resistência de maneira autônoma}

Os alunos podem adquirir através do treinamento de força e resistência experiências corporais e conhecimentos teóricos importantes. Eles aprendem a avaliar e expandir suas capacidades de resistência e de força e, com isso, melhoram suas valências biofísicas, seu acervo de experiências corporais e seu conhecimento teórico. Mais importante é que eles aprendem a treinar a si mesmo, com autonomia e autodeterminação, quando são capazes de adaptar o treinamento para suas necessidades singulares, ou seja, para a singularidade de cada individuo. Eles agem de forma independente e adquirem competências específicas de treinamento.

O projeto aqui descrito foi realizado na escola Municipal Teodoro Sampaio, em Salvador, Bahia, Brasil. O professor da Turma é Flavio Santana que realiza estudos de mestrado na FACED/UFBA Programa de Pós-Graduação em Educação. A Escola Municipal Teodoro Sampaio compõe a Rede de escolas Municipais de Salvador que possui aproximadamente 500 escolas funcionando.

O aqui descrito foi planejado e vivenciado na Universidade Federal da Bahia, no Curso de Licenciatura em Educação Física, com os estudantes da Disciplina 
Prática do Ensino II, durante os estudos sobre as abordagens para o ensino da Educação Física, no semestre letivo de 2014.2. A experiência foi desenvolvida durante a visita cientifica do Professor Dr. Reiner Hildebrandt-Stramann a UFBA para assessorar as mudanças no currículo de formação de professores que estão em curso.

O descrito é a implementação que ocorreu em um dia com os estudantes do sétimo ano escolar, faixa etária entre 12 anos na maioria até os 16 anos. Por ter sido realizada a experiência em um dia não será possível dizer se as variáveis força e resistência melhoraram por este modelo de treinamento neste projeto ${ }^{2}$. A experiência foi realizada no dia 16/09/2014, no horário de 8.00 às 12.00 horas, com 26 alunos do sétimo ano. Foi desenvolvido um exemplo de treinamento com o tema "Os alunos treinam a força e a resistência com autodeterminação". A turma foi dividida em dois grupos: 13 alunos trabalharam com o tema "resistência" e 13 trabalharam com o tema "força".

A preparação da aula exigiu na universidade (UFBA) três etapas anteriores: (a) etapa do seminário teórico para dominar as bases e fundamentos pedagógicos e dos conteúdos específicos a serem tratados, a saber: treinamento de força e resistência; (b) etapa do planejamento do treino na escola : (c) etapa da vivencia e experiência própria, singular, dos alunos da universidade. A última etapa foi a implementação e avaliação do plano de treinamento da resistência e da força na escola Teodoro Sampaio. Investigou-se, também, se o objetivo de ser capaz de treinar-se a si mesmo pode ser realizada numa aula aberta às experiências (comp. Hildebrandt-Stramann, 2009).

Vale ressaltar que com esta experiência articulam-se quatro eixos do currículo de formação dos professores de Educação Física, ou seja, conhecimentos científicos de quatro módulos foram mobilizados a saber: Conhecimentos sobre

\footnotetext{
${ }^{2} \mathrm{~A}$ intenção do texto é descrever metodologicamente o trabalho realizado e não avaliar a melhoria das valências físicas resistência e força dos alunos. Por causa do curto prazo deste projeto não foi investigados e a força e a resistência podem ser melhoradas por este modelo de treinamento.
} 
fundamentos da área da saúde, em especial sobre sistema muscular, esquelético e cardiorrespiratório, conhecimentos sobre energia necessária para o movimento humano e a procedência desta energia; Conhecimentos sobre a práxis pedagógica sobre formação humana e a natureza e especificidade da Educação; conhecimentos sobre o trabalho cientifico - rigoroso de observação coleta e analise de dados; conhecimentos sobre conteúdos específicos - o treino corporal das valências força e resistência.

\subsubsection{O treinamento da força como conteúdo do ensino}

Os estudos de Buskies (2007, p. 46) comprovam que mesmo com cargas baixas os músculos podem alcançar efeitos do treinamento mensuráveis, que podem ser comparados a um treino com pesos pesados. Comprovam também que menos cargas provocam no corpo processos de adaptação que levam a um aumento de rendimento. Para os alunos é indicado como método de treinamento as cargas de força suáveis. Com "suave" é entendido um treino controlado pessoalmente e individualmente, em que a intensidade é controlada através do esforço percebido de maneira subjetiva. Um treinamento de força suave é finalizado bem antes de atingir a carga máxima. Sob um esforço percebido subjetivamente é entendido exatamente esta carga que é percebido e avaliado individualmente por uma pessoa. Assim essa percepção de esforço, que é baseado na percepção humana de nosso próprio corpo, pode ser considerado como um componente subjetivo do treinamento (comp. Lange,2003, p.45). Por causa da carga relativamente reduzida, um treinamento de força suave, do ponto de vista ortopédico e fisiológico, é bem adequado para crianças e jovens na educação física.

Para uma dosagem adequada em educação física, escalas multicelular (escala com muitas etapas) que podem ser usado para uma orientação. Para o treinamento de força com os alunos provaram-se escalas de seis etapas, que são baseados no sistema de classificação da escola. Com base nos valores da escala de "trabalho duro, mas conseguimos" até "era muito fácil" os alunos 
podem se orientar melhor no emprego das cargas. (comp. Baschta, 2008, pag. 71).

\begin{tabular}{|l|l|}
\hline $\begin{array}{l}\text { Valor da } \\
\text { escala }\end{array}$ & Conceito de orientação \\
\hline 1 & $\begin{array}{l}\text { trabalho muito fácil, } \\
\text { quase sem esforço }\end{array}$ \\
\hline 2 & $\begin{array}{l}\text { trabalho fácil, a gente } \\
\text { sente um esforço }\end{array}$ \\
\hline 3 & $\begin{array}{l}\text { trabalho entre fácil e } \\
\text { cansativo }\end{array}$ \\
\hline 4 & trabalho cansativo \\
\hline 5 & $\begin{array}{l}\text { trabalho muito cansativo, } \\
\text { mas conseguimos }\end{array}$ \\
\hline 6 & $\begin{array}{l}\text { trabalho duro, não } \\
\text { conseguimos }\end{array}$ \\
\hline
\end{tabular}

Tabela 1: escala de carga subjeitiva

Os objetivos educacionais gerais eram:

- Promover o desenvolvimento da capacidade da força muscular no contexto da promoção, prevenção e manutenção da saúde com o fortalecimento da capacidade postural.

- O treinamento de força serve para uma extensão da mobilidade individual através de levantamento e sistematização de experiências corporais.

- Através dos processos de treinamento os alunos assimilam e desenvolvem conhecimentos científicos relacionadas com as capacidades corporais (o corpo humano e o movimento).

- Durante do treino conjunto os alunos ampliam sua capacidade de ação social.

- A competência para ser capaz de treinar pode fortalecer a auto-confiança.

- A competência para ser capaz de treinar-se a si mesmo permite uma avaliação e reflexão crítica de serviços externos de treinamento oferecidos, por exemplo, por acadêmias.

A experiência desenvolvida na escola Municipal Teodoro Sampaio foi estruturada nos seguintes passos com os seguintes objetivos especiais: 
1. fase (meia hora): Os alunos devem sentir e através de sentir conhecer a tensão e a função dos músculos.

2. fase (meia hora): Os alunos devem desenvolver suas próprias estações de treinamento para o grupo musculares dos braços, ombros, peito e costa. Eles recebem uma ajuda através de fotos sobre possíveis estações. Eles devem desenvolver e documentar estas estações e depois apresentar para seus colegas. As estações devem ser avaliadas: Que grupo de músculos é treinando? (ver as fotos 1-8).

3. fase (meia hora): Os alunos recebem uma introdução nas dimensões subjeitivas de treinamento (veja tabela 1). Eles recebem a tarefa de escolher uma das estações apresentadas e nesta estação treinar com as seguintes repetições:

Série 1: 5 repetições

Série 2: 10 repetições

Serie 3: 15 repetições

Serie 4: 20 repetições

Junto com esta tarefa os alunos recebem uma informação sobre carga de treinamento "suave" baseada numa tabela da percepção subjetiva de esforço:

1 = trabalho muito fácil, quase sem esforço

$2=$ trabalho fácil, a gente sente um esforço

$3=$ trabalho entre fácil e cansativo

$4=$ trabalho cansativo

$5=$ trabalho muito cansativo, mas conseguimos

6 = trabalho duro, não conseguimos

Os alunos devem entender a tarefa e repetir a tarefa.

4. fase: Os alunos devem realizar os exercícios segundo as repetições ligado com a tarefa de avaliar as repetições com a tabela da percepção subjetiva. A avaliação deve ser documentada (comp. tabela 2).

5. fase: Os alunos recebem a tarefa de escolher uma estação e executar três séries. Eles devem terminar com cada série quando chegam à uma sensação de 
carga tolerável. Eles devem anotar os números respectivos de repetição numa tabela (comp. tabela 3). O objetivo desta tarefa é desenvolver um sentido subjetivo de carga e treinar segundo este sentido subjetivo.

\begin{tabular}{|c|c|c|}
\hline \multicolumn{2}{|l|}{ Estação } & \multirow{2}{*}{$\begin{array}{l}\text { A sensação subjetiva de carga } \\
\text { Muito/ fácil/media/ difícil/muito } \\
\text { fácil dificil }\end{array}$} \\
\hline série 1 & 5 repetições & \\
\hline & Intervalo $1 \mathrm{~min}$ & \\
\hline \multirow[t]{2}{*}{ série 2} & 10 repetições & $\begin{array}{l}\text { Muito/ fácil/ media/ difícil/ muito } \\
\text { fácil difícil }\end{array}$ \\
\hline & Intervalo $1 \mathrm{~min}$ & \\
\hline \multirow[t]{2}{*}{ série 3} & 15 repetições & $\begin{array}{l}\text { Muito/ fácil/media/ difícil/ muito } \\
\text { fácil difícil }\end{array}$ \\
\hline & Intervalo $1 \mathrm{~min}$ & \\
\hline série 4 & 20 repetições & $\begin{array}{l}\text { Muito/ fácil/media/ difícil/ muito } \\
\text { fácil difícil }\end{array}$ \\
\hline
\end{tabular}

Tabela 2: Avaliação das repetições

\begin{tabular}{|c|c|}
\hline \multicolumn{2}{|l|}{ Estação } \\
\hline Série & $\begin{array}{l}\text { Numero de repetições que levam você à } \\
\text { uma sensação media de carga }\end{array}$ \\
\hline \multicolumn{2}{|l|}{ Série 1} \\
\hline Intervalo $1 \mathrm{~min}$ & |---------------------- \\
\hline \multicolumn{2}{|l|}{ Série 2} \\
\hline Intervalo $1 \mathrm{~min}$ & ------------------------ \\
\hline Séria 3 & \\
\hline
\end{tabular}

Tabela 3: Sensação de carga 


\subsubsection{Realização das aulas e resultados dos treinos da força}

Aqui não é o lugar de descrever cada fase de aula, mas através de observações podemos constatar que todos os alunos participaram bem motivados na realização das tarefas. Às vezes foi necessário intervir no processo e explicar de novo a tarefa. Durante as aulas eles trabalharam em grupos, demonstraram seus exercícios uns aos outros, comparam os resultados. Foi uma verdadeira aprendizagem social o compartilhamento dos resultados do cumprimento das tarefas e a analise dos resultados de cada individuo singular.

Eles conseguiram criar e construir suas próprias estações, segundo o que demonstram as fotos. Importante foi que eles conseguiram explicar para seus colegas que grupo de músculos foram treinados com a situação auto-escolhida e autoconstruída pelos alunos. Isso significa que eles assimilaram primeiros conhecimentos sobre a constituição do próprio corpo em especial sobre o sistema muscular, esquelético e cárdio-vascular-respiratório.

Além disso, podemos constatar que os alunos foram capazes de construir um relacionamento entre esforço (número de repetições) e a sensação subjetiva de carga. Os níveis1 e 6 não foram mencionados por ninguém. Isto é, o esforço "trabalho muito fácil, quase sem esforço" e, o esforço "trabalho duro, não conseguimos" não foram sentidos. O seguinte gráfico mostra como um resultado o sentido subjetivo de carga.

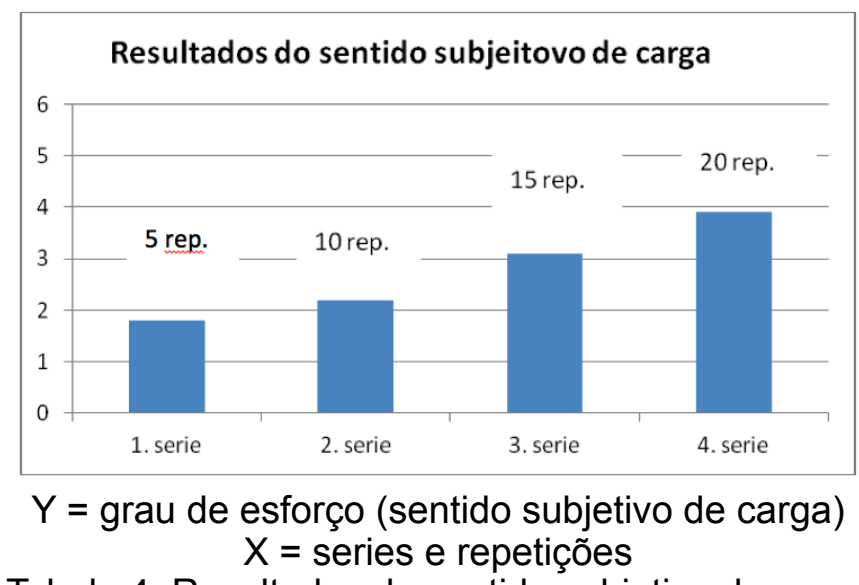

Tabela 4: Resultados do sentido subjetivo da carga 
No eixo-x são apresentados as séries e suas respectivas repetições. No eixo-y é dada o grau de esforço. Vê-se claramente que a percepção de esforço aumenta linearmente com o número de repetições. Embora o grau do esforço é baixo em cinco repetições (5 rep.), 20 repetições são percebidas quase como muito cansativo. No esforço de 15 a 20 repetições os alunos dizem que têm um esforço percebido como médio. É claro que um treino da força que seria realizado de um período mais longo (por exemplo,4 semanas) baseado no princípio do sentido subjetivo da carga, também levaria a um aumento significativo da força.

Realizamos um projeto de implementação com os alunos, no entanto, recomenda-se a continuação de tal programa de treinamento de força durante um período, por exemplo quatro semanas, de modo que os alunos possam realmente notar uma mudança da força em termos de um aumento de força.

\subsubsection{Resumo}

O projeto proposto é baseado numa concepção didática de ensino aberto às experiências. Tais propostas de ensino promovem e apóiam a autonomia e a auto-responsabilidade dos alunos. Mas, para tanto cabe ao professor dominar o conteúdo para problematizar a realidade atual com os alunos, sobre o tema. Cabe ao professor instrumentalizar os alunos com o acesso ao conhecimento clássico sobre treinamento, ou seja, o conhecimento fundamental, atual, cientifico sobre treinamento. Cabe ao professor transmitir este conhecimento sem o qual os alunos não tem como assimilar, criar oficinas e treinar a força. Cabe a escola oferecer as condições de infraestrutura para que as seções nas aulas possam ocorrer. Tem sido demonstrado que os alunos podem realizar de modo independente o treinamento de força, com base em sua percepção da carga subjetiva e no conhecimento assimilado nas aulas de Educação Física. Eles começaram a assimilar e aprender a treinar a si mesmo. Concluímos que as aulas abertas a experiência dos estudantes dependem da transmissão-assimilação dos conteúdos clássicos tratados nas aulas que permitem a construção da subjetividade-objetividade humana. 


\section{REGISTRO FOTOGRAFICO DAS ESTAÇOES REALIZADAS DURANTE A AULA NA ESCOLA MUNICIPAL TEODORO SAMPAIO SAVADOR BAHIA} 16/09/2014. Sob a coordenação do professor Dr. Reiner Hildebrandt-Stramann, Dra. Celi Zulke Taffarel e Professor Flavio Santana, com a participação dos alunos do Curso de Educação Física da UFBA.

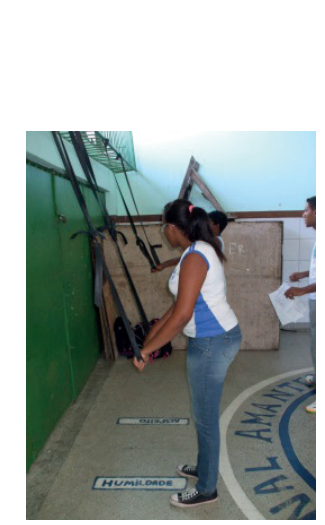

Estação 1

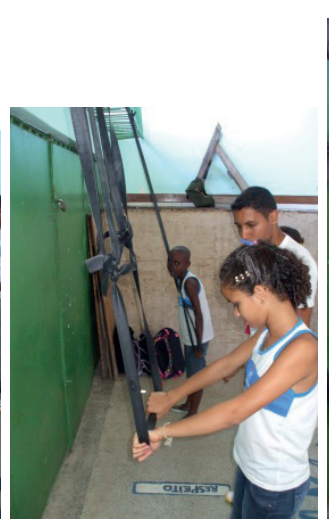

Estação 1

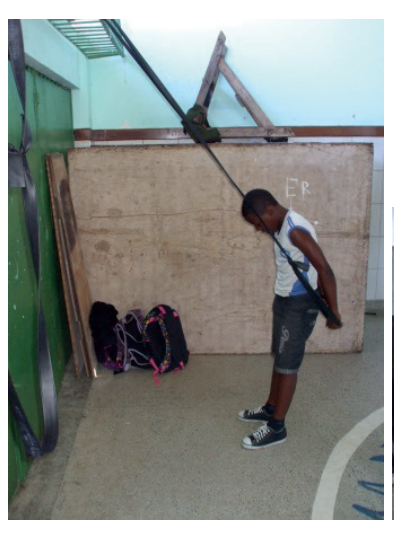

Estação 1

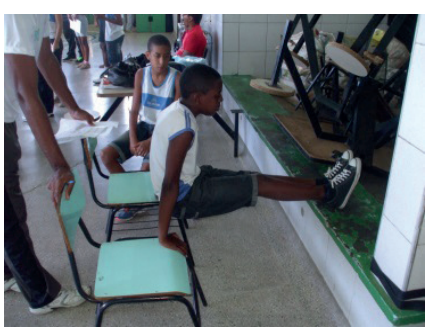

Estação 2

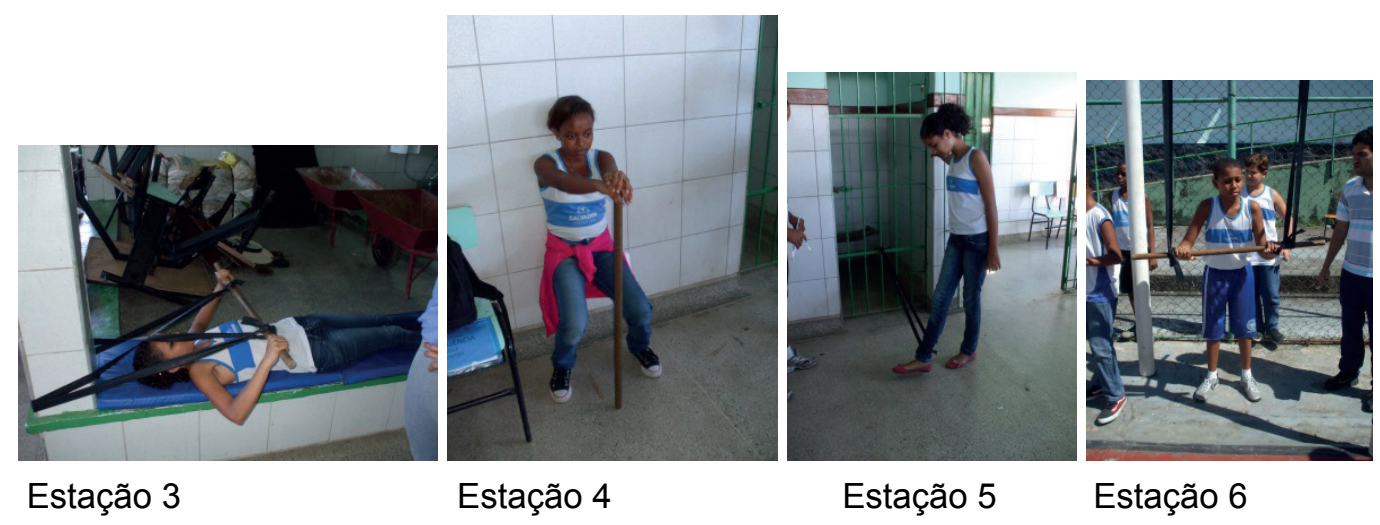

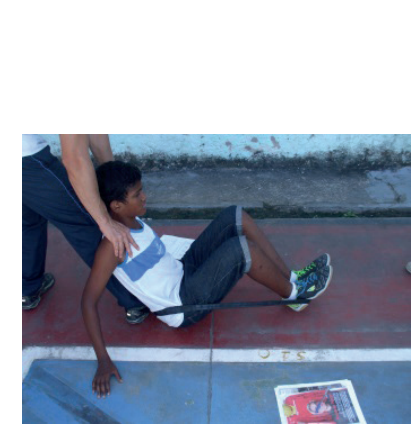

Estação 7

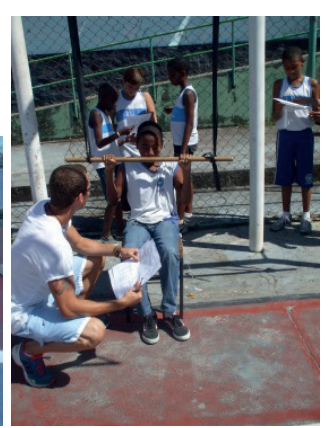

Estação 8

Fotos 1 - 8: As estações de treinamento da força, desenvolvidas pelos alunos da escola Teodoro Sampaio. 


\subsection{O treinamento da resistência como conteúdo do ensino}

A resistência é definida como a capacidade para se obter um estado de resistência ao cansaço. Capacidade de prolongar resistência a fadiga. Os objetivos deste curso com os alunos são: Os alunos devem aprender a se esforçar corretamente o que significa:

- sabem avaliar a carga por meio de suas sensações e percepção de esforço e baseado nesta avaliação, também, saber regular a intensidade do exercício.

- devem ganhar uma competência específica de auto-treinamento da valência resistência física.

- devem aprender a medira as consequências do esforço no sistema cardíacovascular respiratório.

O primeiro passo para tal e aprender a medir batimentos cardíacos controlando no pulso e ou no pescoço. No segundo passo eles devem conhecer a escala nova de avaliação (comp. tabela 4).

\subsubsection{As tarefas}

\section{1. tarefa}

Captar os batimentos cardíacos apalpando o pulso. Medir por um minuto o pulso (o seu ritmo cardíaco) sentado. Em seguida, contar o número de suas respirações por minuto (comp. tab. 5).

Na sequência realizar 20 agachamentos. Medir imediatamente após o agachamento o pulso por 15 segundos. Multiplicar este número por quatro e anotar o resultado na tabela. Também contar o número de respirações por minuto. Repetir as medições de novo, depois de dois e de quatro minutos. Explicar as diferenças nos resultados. 


\begin{tabular}{|c|c|c|}
\hline \multicolumn{1}{|c|}{ Tempo de medição } & $\begin{array}{c}\text { batimentos cardíacos por } \\
\text { minuto }\end{array}$ & Respirações por minuto \\
\hline Sem movimento & & \\
\hline Depois de 20agachamentos & & \\
\hline Dois minutos mais tarde & & \\
\hline Quatro minutos mais tarde & & \\
\hline
\end{tabular}

Tab. 5: Tabela para as medidas do pulso e das respirações

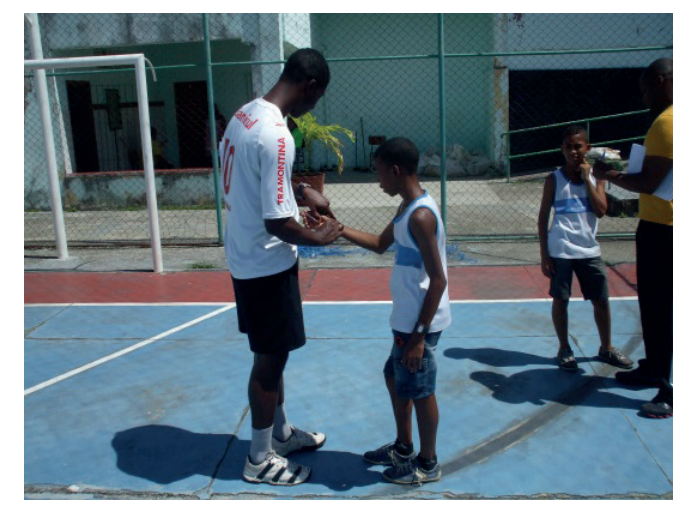

Foto 9: Os alunos aprendem medir os batimentos cardíacos em um minuto apalpando o pulso durante 15 segundos e multiplicando por quatro.

\section{2. tarefa:}

a) Ler os dados da escala abaixo.

\begin{tabular}{|c|c|c|}
\hline 1 & muito fácil & Sem esforço, assim como andar \\
\hline 2 & fácil & $\begin{array}{l}\text { Devagar, a resposta cardiovascular quase } \\
\text { imperceptível }\end{array}$ \\
\hline 3 & media - fácil & $\begin{array}{l}\text { Esforço na área de bem-estar, uma conversação é } \\
\text { possível }\end{array}$ \\
\hline 4 & media & $\begin{array}{l}\text { A respiração torna-se palpável e audível, é } \\
\text { possível de falar, mas já mais complicado }\end{array}$ \\
\hline 5 & difícil & A carga é claramente percebida, fica difícil falar \\
\hline 6 & muito difícil & $\begin{array}{l}\text { Respiração rápida, talvez as pernas doem, } \\
\text { resistência perto de limite, tempo maior, } \\
\text { cansativo, só pouco tempo realizável }\end{array}$ \\
\hline
\end{tabular}

Tab. 6: A escala de avaliação do esforço de resistência 
b) Procurar um cone espalhado pela quadra como o ponto de partida. Correr um minuto na pista em torno dos cones em um tempo/ritmo que permita se sentir em relação a escala de classificação, como um esforço "médio". Lembrar em que cone iniciou a corrida. Correr e contar o número de cones, que passa por um minuto ( $O$ sinal de iniciação e de parar são predados pelo professor). Escreve o resultado numa tabela (comp. tab. 7 ).

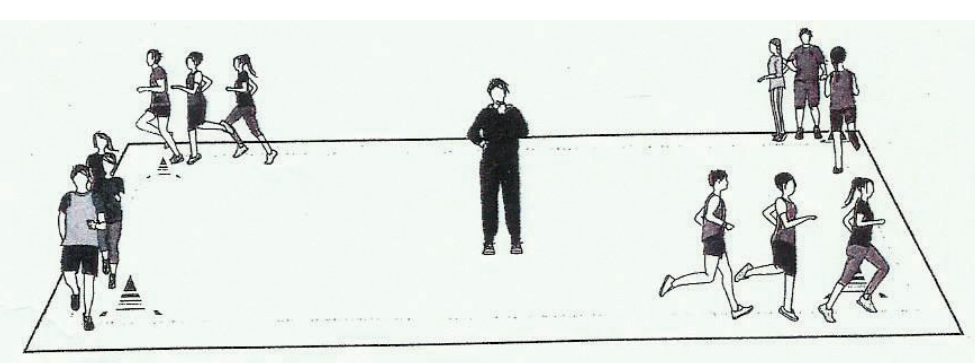

Ilustração 1: A corrida no pátio em torno dos cones

c) Realizar uma pausa de um minuto.

d) Repetir a corrida. Correr com o mesmo ritmo/ a mesma velocidade de antes.

Realizar o controle na base do número de cones em que você está correndo passado.

e) Escolher uma outra carga da escala de classificação (por exemplo,"pesado") e repetir o experimento.

\begin{tabular}{|c|c|c|}
\hline escala de classificação & Tempo de corrida & Numero de cones \\
\hline media & 1 minuto & \\
\hline media & 1 minuto & \\
& & \\
\hline & & \\
\hline
\end{tabular}

Tab. 7: O número de cones

\section{3. tarefa:}

Os alunos devem correr 6 minutos. Nestes 6 minutos eles devem correr um trajeto tão longo quanto Ihes seja possível. O trajeto é a volta sobre o campo de 
voleibol que tem em cada esquina um cone.Devem ser contados os números de cones que cada aluno está passando durante a corrida.

\section{4. tarefa}

Os alunos devem correr novamente 6 minutos com uma percepção subjetiva de esforço como média na escala subjetiva de esforço. Eles devem contar os números de cones em que cada aluno está correndo passando.
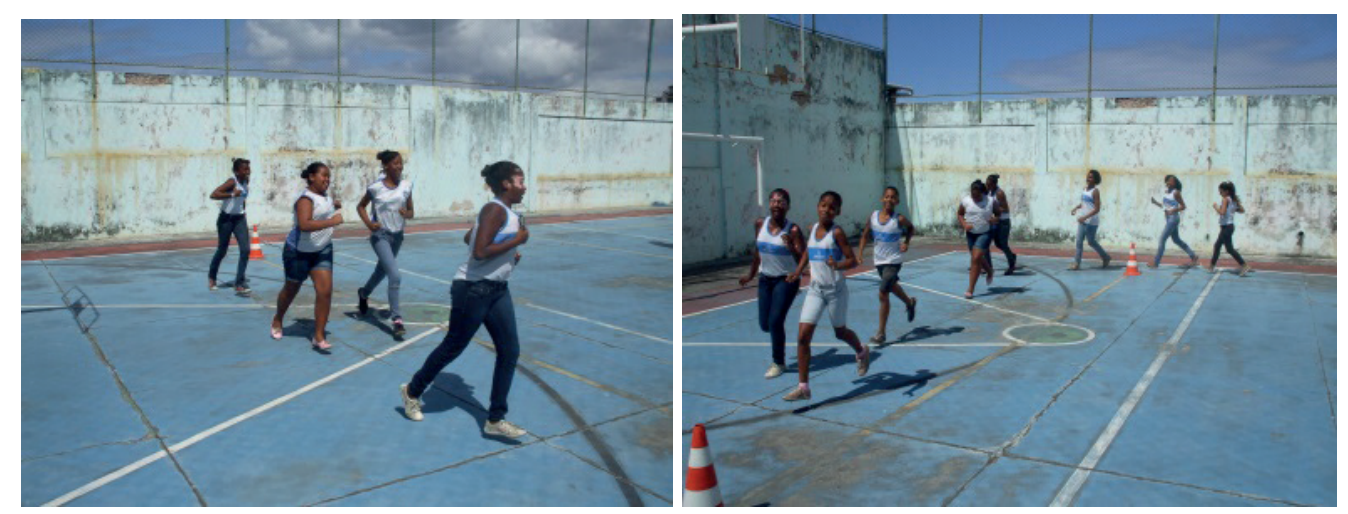

Foto 10 e 11: Os alunos correm com um esforço subjetivo da carga auto planejado apos a primeira experiência.

\subsubsection{A avaliação}

Em primeiro lugar os alunos aprenderam medir os batimentos cardíacos e a respiração através do pulso e no pescoço. Esse foi o pré-requisito para a realização da sequências de tarefas e suas reflexões.

Na segunda tarefa constatamos que os alunos já têm uma boa auto-avaliação. Eles passaram na primeira corrida, em média, 12 cones. Na segunda corrida, eles passaram 14 cones em média. Na reflexão eles chamaram atenção ao fato de que na primeira corrida não tinham noções físicas de uma tensão média. Por isso, eles tinham inicialmente corrido um pouco mais lento. Com base nas experiências de carga da primeira corrida eles foram capazes decorrer mais rápido com uma carga média. Na terceira corrida, alguns queriam "jogar" com a carga, ou seja, alguns alunos escolheram uma carga elevada, alguns uma mais baixa, mas a 
maioria deles novamente escolheu uma carga média. Para os alunos, o resultado foi interessante: Apesar da alta carga eles passaram, em média, menos cones do que antes com a carga média. Mas, também, os alunos que correram com uma carga média ou baixa passaram quase o mesmo número dos cones. Eles apresentaram as seguintes explicações para estes resultados conforme segue abaixo:

1. Na terceira corrida, o esforço das duas primeiras rodadas se faz perceptível. Os alunos sentiram, depois de duas corridas, o cansaço. Portanto, não conseguiram correr muito mais rápido. Disseram: Se a gente corre mais rápido fica rapidamente fora do ar.

2. Disseram: Com uma carga média a gente não chega com dificuldades respiratórias. Por isso a gente pode correr no mesmo ritmo como nas duas primeiras rodadas.

3. Os alunos fizeram uma outra observação importante. Comparamos resultados das corridas: O número de cones que foram passados pelos alunos individualmente, diferiu significativamente entre os alunos. Na primeira corrida o número de cones ficou entre 9-15, na segunda corrida entre 12-20. A partir deste resultado, os alunos concluíram facilmente que a carga média de aluno para aluno é diferente. Cada aluno tem uma percepção subjetiva do esforço.

Os resultados da terceira corrida foram como esperávamos. Os alunos correram todos em um ritmo significativamente diferente, mas para que pudessem realmente manter os seis minutos. É claro que houveram alguns alunos que estavam correndo muito rápido e por isso terminaram de correr antes dos seis minutos. Mas a maioria conseguiu. Escolheram bem uma carga média, o que Ihes permitiu correr os 6 minutos com persistência.

\subsubsection{A interpretação pedagógica sobre o treinamento na escola}

Do ponto de vista do treino pedagógico os alunos conseguiram relacionar as cargas de treinamento de maneira coerente. Eles tiram suas conclusões sobre 
o esforço percebido subjetivo para os seus limites de carga individual. De tudo isso eles tiram consequências para a configuração de carga do esforço para as próximas aulas. O que os alunos fizeram:

- Eles sempre refletem e baseado nesta reflexão eles regulam sempre de novo suas cargas e seus esforços de treino. Quem sabe fazer isso desta maneira tem a competência de definir seus próprios objetivos e sabe comparar os objetivos com as exigências da situação de maneira variável.

- A qualidade especial de treino nas aulas de Educação Física depende da competência do aluno de achar seu equilíbrio biológico individual. Na teoria de treino se chama este estado do equilíbrio biológico como homeostase ${ }^{3}$. 0 processo de treino sempre provoca um estado do desequilíbrio, que leva, depois de um relaxamento, para um novo equilíbrio biológico. E isso é um dos objetivos centrais de um processo de treino nas escolas: Os alunos devem ter a liberdade de procurar através de atividades autodeterminadas de treinamento encontrar o estado de homeostase. O estado de homeostase e individualmente diferente. Por isso é necessário individualizar o processo de treino, tendo por base a própria capacidade do estudante de perceber seu esforço de maneira subjetiva.

\section{Conclusões}

Em todos os dois experimentos fica claro que os alunos são capazes de buscar sua carga de acordo com suas sensações e percepção subjetiva. Consequentemente,

${ }^{3}$ Trazemos para definir Homeostase a contribuição localizada no sitio: http://www.significados.com.br/homeostase/

"Homeostase é a capacidade do organismo de apresentar uma situação físicoquímica característica e constante, dentro de determinados limites, mesmo diante de alterações impostas pelo meio ambiente. Para conservar constante as condições da vida, o organismo mobiliza os mais diversos sistemas, como o sistema nervoso central, o endócrino, o excretor, o circulatório, o respiratório etc. Em 1859 o fisiologista francês Claude Bernard disse que todos os mecanismos vitais, por mais variados que sejam, não têm outro objetivo além da manutenção da estabilidade das condições do meio interno. Em 1929, W. B. Cannon chamou essa estabilidade de homeostase (do grego homoios -"o mesmo" e stasis -"parada"). Ele não se referia a uma situação estática, mas a algo que varia dentro de limites precisos e ajustados. Esses limites de variação e os mecanismos de regulação constituem boa parte do estudo da Fisiologia." 
o aluno é capaz de controlar seu processo de treinamento. Podemos ver que os alunos têm uma percepção subjetiva do esforço bem desenvolvido. O exemplo mostra que um ensino aberto às experiências também pode ser utilizado como um tema a partir da teoria de treinamento. Importante é a capacidade didática do professor. Ele precisa conhecimentos didáticos profundos sobre a teoria do desenvolvimento humano, a teoria pedagógica, metodologia do ensino e a teoria geral do treinamento.

Precisa de conhecimentos específicos sobre os objetos da cultura corporal entre os quais constam os conhecimentos clássicos sobre treino corporal. Nessas aulas, foram transmitidos noções básicas aos alunos da Escola Municipal Teodoro Sampaio. Constatamos que eles assimilaram conhecimentos e aprenderam a configurar o seu processo de treinamento de forma independente e auto responsável, considerando as suas sensações e percepção que se ampliou a partir do conhecimento didaticamente organizado na aula de Educação Física. Os alunos não só aprenderam a projetar treinamento de força e de resistência, mas eles também adquiriram conhecimentos sobre como organizar com autodeterminação seu próprio treino corporal.

Nós professores pesquisadores e alunos da universidade aprendemos que o desenvolvimento cientifico decorre de respostas concretas a perguntas vitais colocadas para nós. É vital contribuir para elevar o pensamento teórico dos alunos, é vital fazer com que a escola cumpra a sua função social que é garantir o acesso ao conhecimento clássico para desenvolver a personalidade dos alunos.

O avanço científico em geral e em especial na Teoria Pedagógica da Educação Física decorre desde diálogo científico e os saltos qualitativos que podemos e devemos dar em nossas elaborações que dependem muito de agirmos de forma colaborativa assimilando, incorporando e avançando em nossas propostas pedagógicas. 


\section{Bibliografia}

BASCHTA, Martin. (2008). Subjektive Belastungssteuerung im Sportunterricht. Trainingspädagogische Überlegungen und empirische Befunde zum Trainieren im Schulsport. Göttingen: Cuvillier.

BUSKIES, Werner. (2007). Sanftes Krafttraining. In Medical Sports 2, p. 4650. Heinz, Nino. \& Wichmann, Klaus. (2010). Schüler trainieren ihre Kraft selbst. Sportunterricht 59 (9), p. 264-270.

HEYWARD, Vivian H. (2004) A avaliação Física e prescrição de exercícios: Técnicas avançadas. 4 ED. Porto Alegre: Artmed.

HILDEBRANDT-STRAMANN, Reiner. (2013). Textos pedagógicos sobre ensino da Educação Física. Brasilien: ljui/RS : Editora Uniijui. 4. Edição.

HILDEBRANDT-STRAMANN, Reiner. \& TAFFAREL, Celi. (2007). Currículo e Educação Física. Formação de Professores e Práticas nas Escolas. Brasilien: Ijui/RS : Editora Uniijui.

HILDEBRANDT-STRAMANN, Reiner. (2009). Educação Física aberta à experiência. Uma concepção didática em discussão. Rio de Janeiro: Imperial NOVO MILÊNIO.

LANGE, Harald. (2003). Was ist "Training" - wie wird Training gestaltet? In V. Scheid \& R. Prohl (Hrsg.), Kursbuch Sport 2: Trainingslehre (p. 11-53). Wiesbaden: Limpert. 
LURIA, Alexander Romonovich.(1991).Curso de Psicologia Geral - Sensaçoes e percepção. Rio de Janeiro, Civilização Brasiliense, Vol. II.

MARTINS, Ligia Márcia. (2013) O Desenvolvimento do Psiquismo e a Educação Escolar: Contribuições à luz da psicologia histórico-cultural e da pedagogia históricocritica. Campinas/SP: Autores Associados.

SAVIANI, Dermeval. (2013). Pedagogia Histórico-Critica. 11 Ed. Campinas/SP: Autores Associados.

TUBINO, Manoel José Gomes. (1984) Metodologia cientifica do treinamento desportivo. 3 Ed. São Paulo: Ibrasa. 
KNOW TO TRAIN YOURSELF: WHY AND HOW WE MUST TEACH TRAINING IN PHYSICAL EDUCATION CLASSES?

\begin{abstract}
The text presents scientific arguments about the physical training at school from a concrete experience at the Municipal School Teodoro Sampaio, Salvador Bahia, Brazil.
\end{abstract}

Keywords: Body training. Physical education. School.

\title{
¿SABER ENTRENAR A SI MISMO: POR QUE Y COMO DEBEMOS ENSEÑAR ENTRENAMIENTO EN CLASES DE EDUCACIÓN FÍSICA?
}

Resumen: El texto presenta argumentos científicos acerca del entrenamiento físico en la escuela a partir de una experiencia concreta en la Escuela Municipal Teodoro Sampaio, Salvador, Bahia, Brasil.

Palabras clave: Entrenamiento corporal. Educación física. Escuela. 